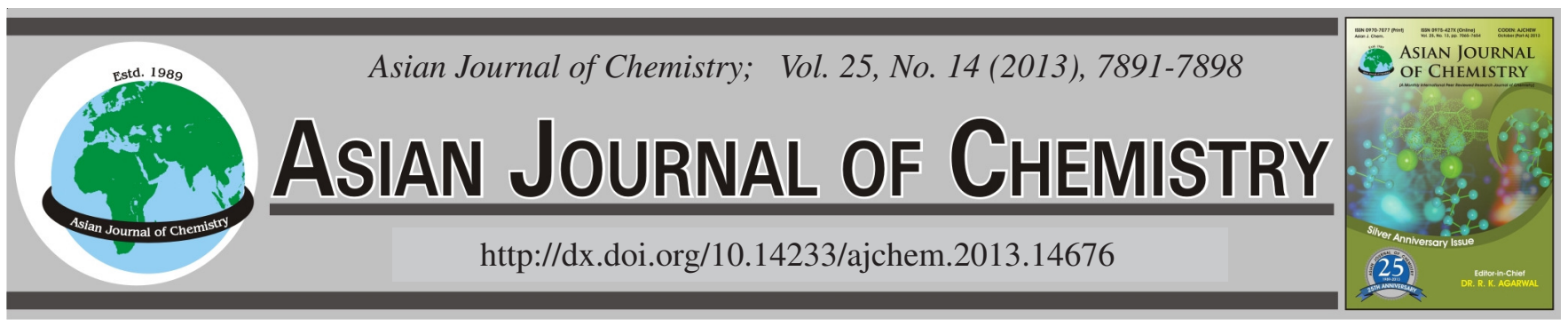

\title{
Photolysis of Dimethyl Phthalate via Microwave Discharge Electrodeless Iodine Lamp: Parameters, Feasibility and Mechanism
}

\author{
Y.J. ZHAO ${ }^{1,2}$, C. YAN ${ }^{1}$, D.H. GU ${ }^{1}$, J. HE ${ }^{1, *}$ and H.Q. Hou ${ }^{1}$
}

${ }^{1}$ Department of Environmental Science and Engineering, No. 220 Handan Road, Fudan University, Shanghai 200433, P.R. China

${ }^{2}$ College of Biological Chemical Science and Engineering, Jiaxing University, Jiaxing 314001, P.R. China

*Corresponding author: Tel./Fax: +86 21 65642181; E-mail: hejerry@ vip.sina.com; zyjun2007@126.com

(Received: 15 October 2012;

Accepted: 22 July 2013)

AJC-13835

\begin{abstract}
This study reports, the photolysis of dimethyl phthalate using $206.2 \mathrm{~nm}$ UV light emitted from a locally made novel microwave discharge electrodeless iodine lamp (MDEIL). Optimal preparation parameters of MDEIL were determined as follows: iodine amount, $0.5 \mathrm{mg}$; krypton pressure, 2 torr and input power, $65 \mathrm{~W}$. Removal efficiency of dimethyl phthalate reached $97.5 \%$ at 20 min irradiation time and $20 \mathrm{mg} \mathrm{L}^{-1}$ initial dimethyl phthalate concentration. A possible mechanism of the dimethyl phthalate photolysis may involve electron transition reactions and reactions with hydroxyl radicals. The intermediates were identified as phthalic acid and 2-hydroxyl acid methyl esters. Results from this study may help promote further studies on the feasibility of MDEIL to decompose more aqueous organic contaminants, including other refractory contaminants.
\end{abstract}

Key Words: Microwave discharge electrodeless iodine lamp, Dimethyl phthalate, $206.2 \mathrm{~nm}$ UV light, Aqueous organic contaminant.

\section{INTRODUCTION}

Phthalate acid esters (PAEs) comprise a large family of chemical compounds most extensively used as cellulose film coating, adhesives and plasticizers in industrial production. The yield of phthalate acid esters had already reached as much as 2.7 million ton per year in $1997^{1}$. These compounds are released to the environment during large production and utilization process because they are physically bound to polymer chains $^{2,3}$. Keith and Telliard ${ }^{4}$ estimated that at least $23,000 \mathrm{Mg}$ of phthalate acid esters are released into the environment annually. Human health and natural environmental concerns about phthalate acid esters have been recognized for several years $^{5,6}$. Phthalate acid esters accumulate in the natural environment and are poisonous to all kinds of aquatic organisms, which are at the base food chain in marine and fresh water environments ${ }^{2}$. Several kinds of phthalate acid esters, as well as their degradation products and metabolites, have been suspected of causing adverse effects on human health ${ }^{7}$. Jobling et al. ${ }^{8}$ and Allsopp et al. ${ }^{9}$ suggested that phthalate acid esters are endocrine-disrupting chemicals that may promote chromosome injuries in human leukocytes and interfere with the reproductive system. Several of these esters have been included in the priority list of pollutants of various national and supranational organizations because of their broad diffusion and potential risks for both human health and the environment ${ }^{10}$.
Dimethyl phthalate (DMP) is one of the most represented phthalate acid esters and commonly detected in natural ecosystems. This ester is included in the list of proposed substances recognized as significant environmental contaminant published by European Union ${ }^{11}$. Furthermore, according to the US Clean Water Act, dimethyl phthalate should be considered as a priority toxic pollutant ${ }^{12}$. Dimethyl phthalate has a short-chained ester with two carboxyl groups on the aromatic ring ${ }^{13}$. This compound is a relatively stable material in the environment and its hydrolysis half-life has been estimated to be approximately 20 years $^{14}$. Studies on dimethyl phthalate biodegradation in water, sludge and sediment have shown a low biodegradation rate ranging from days to months ${ }^{14,15}$. Only a few studies have reported the removal of dimethyl phthalate, except those on photo catalytic degradation and photolysis ${ }^{6,10,16}$. In addition, phthalate acid esters are partly relatively photo resistant ${ }^{13,15}$. Hizal et al..$^{17}$ even suggested that the decomposition quantum yields of phthalate was $<0.03$. Thus, finding a satisfactory photolysis treatment to decompose dimethyl phthalate is of great practical significance.

The field of photolysis frequently focus on electrodeless lamp (EL) placed directly into a reaction mixture ${ }^{15-17}$. A number of studies have described a photolysis reactor consisting of mercury-electrodeless lamp, which mainly radiates 185, 253.7 and $365 \mathrm{~nm} \mathrm{UV} \mathrm{light}^{18}$. Although the $185 \mathrm{~nm}$ UV has relatively 
higher photon energy enough to break chemical bonds of most esters, its absorption coefficient for several organic compounds and photon-distance in water $(c a .300 \mu \mathrm{m})$ are too short for large-scale applications ${ }^{19}$. By contrast, the 253.7 and $365 \mathrm{~nm}$ UV light encounter difficulty in breaking most chemical bonds directly due to their lower photon energies (despite longer photon-distances). The conventional solution is the use of oxidants to absorb UV to generate active hydroxyl radicals $\left(\mathrm{HO}^{\circ}\right)$ that can be utilized to break chemical bonds and attack different electron-rich sites within the mean lifetime of a few nanoseconds in a nonselective way ${ }^{20,21}$. However, overdose oxidants added to the treated solution can interfere with photolysis $^{22}$.

Therefore, proper UV light range (e.g., 190-210 nm UV light) has been believed to potentially decompose ester contaminants (e.g., dimethyl phthalate) efficiently.

Xia et $a l .{ }^{23}$ suggested that electrodeless lamp, consisting of a glass tube (quartz or Pyrex) filled under a reduced pressure with krypton-iodine mixture gas and excitable substance iodine, can generate $206.2 \mathrm{~nm}$ UV light under microwave. Hence, a microwave discharge electrodeless iodine lamp (MDEIL) has been employed as a new source pattern of UV light in the current research. The internal materials (kryptoniodine mixture gas and excitable substance iodine) of the MDEIL absorb microwave energy to form stable UV-emission discharge plasma. This lamp is quite different from conventional electrodeless lamp usually energized by an electric field between the electrodes. This MDEIL has a relatively longer photon-distance (206.2 nm UV light) compared with the 185 $\mathrm{nm}$ UV light in aqueous solution and most organic compounds exhibit strong absorption in the vicinity of $206.2 \mathrm{~nm}$. The 206.2 $\mathrm{nm}$ UV light has enough photon energy to directly break most chemical bonds. Thus, MDEIL is advantageous due to of its higher UV radiant power, longer UV emitting lifetime and more adaptable device shape ${ }^{24}$. In addition, the MDEIL 206.2 nm UV light may be a promising device for the photolysis of ester contaminants in a solution. However, to the best of our knowledge, available reports on the parameters to produce a MDEIL (206.2 nm UV) and on the photolysis of dimethyl phthalate contaminant using MDEIL $206.2 \mathrm{~nm}$ UV light are rare.

This study reports, for the first time, the photolysis of dimethyl phthalate using $206.2 \mathrm{~nm}$ UV light emitted from a locally made novel MDEIL. The essential characteristics and preparation parameters of the MDEIL (including the value of krypton, iodine and input power) were examined to optimize the preparation procedure. Several minor details on the general procedure required to prepare an electrodeless lamp are often omitted for conciseness of the presentation. However, individuals who are interested in fabricating an electrodeless lamp is faced with fragmentary information dispersed in the literature because these omitted details are actually critical in producing a proper and highly efficient electrodeless lamp ${ }^{18}$. Therefore, the preparation of the MDEIL was explored experimentally and meticulously described in detail in this research. In addition, the degradation products of dimethyl phthalate were analyzed in detail. The intermediates were identified via gas chromatography-mass spectrometry (GC-MS) techniques. Accordingly, the photolysis mechanism of dimethyl phthalate was also clarified. The feasibility of using this MDEIL device and photolysis technology was elucidated by the degradation efficiency of dimethyl phthalate. Influencing factors, such as irradiation time and initial dimethyl phthalate concentration, were also studied.

\section{EXPERIMENTAL}

Krypton (4.8 grade) and oxygen (99.99 \%) were both purchased from Shanghai Pujiang Specialty Gases Company (Shanghai, P.R. China). Iodine (99.999\%, beads), dimethyl phthalate (AR grade), $1 \mathrm{M} \mathrm{NaOH}$ (AR grade), $0.5 \mathrm{M} \mathrm{HCl}$ (AR grade), hydrofluoric acid and ethanol were all purchased from Sinopharm Group (Shanghai, P.R. China). Distilled water and soapy water were both purchased from Fudan University Drug Warehouse.

The dimethyl phthalate used in this study was of analytical grade. The molecular structure and absorbance spectrum of this compound are shown in Figs. 1a-b, respectively. The dimethyl phthalate solution was obtained by dissolving analytes in distilled water; its initial concentration was $8 \mathrm{mg}$ $\mathrm{L}^{-1}$. The initial $\mathrm{pH}$ value of the dimethyl phthalate solution was adjusted to 6.8 using a $1 \mathrm{M} \mathrm{NaOH}$ (AR grade) and $0.5 \mathrm{M}$ $\mathrm{HCl}$ (AR grade) solution. The $\mathrm{pH}$ buffer solution was nonessential because the change in $\mathrm{pH}$ was less than 0.2 in the solution during the experimental period. The aqueous $10 \%$ hydrofluoric acid was obtained by dissolving hydrofluoric acid in distilled water.

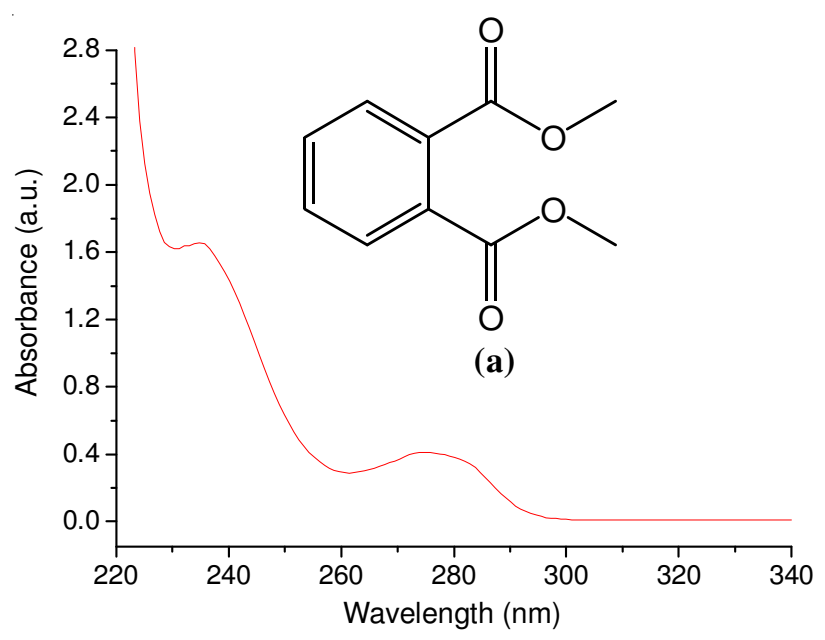

(b)

Fig. 1. Characteristics of dimethyl phthalate: (a) chemical structures and (b) absorbance spectrum

Setup: The locally made MDEIL comprised an electrodeless lamp and a microwave generator. A $2.45 \mathrm{GHz}$ microwave generator was prepared with the assistance of Yalian Microwave Technology Company (Shanghai, P.R. China). The microwave generated high voltage transmitted via an electrical cable (2) to a magnetron (3) to establish a uniform microwave field in the resonance cavity (4) (Fig. 2). The quartz tube was filled with a fixed amount of krypton-iodine gas mixture and excitable substance iodine and was served as the MDEIL was inserted into the cavity. The output microwave was enough to ignite 
the electrodeless discharge lamp (5) when the microwave generator (1) was turned on, with certain amount of input electrical power supply. An MDEIL was then ignited and radiated $206.2 \mathrm{~nm}$ UV light that acted on the dimethyl phthalate in the container, leading to the photolysis of the contaminants. The remaining part of the MDEIL outside the cavity was fixed at the center of a quartz sleeve (6) to serve as the dimethyl phthalate photolysis reactor with one end inserted into the resonant cavity. The quartz sleeve (6) was set between the MDEIL and the solution was utilized to prevent direct contact. All the experiments were performed at atmospheric pressure and temperature $\left(27 \pm 5^{\circ} \mathrm{C}\right)$ with $c a .55 \%$ relative humidity. The dimethyl phthalate solution was treated on the condition of oxygen saturation.

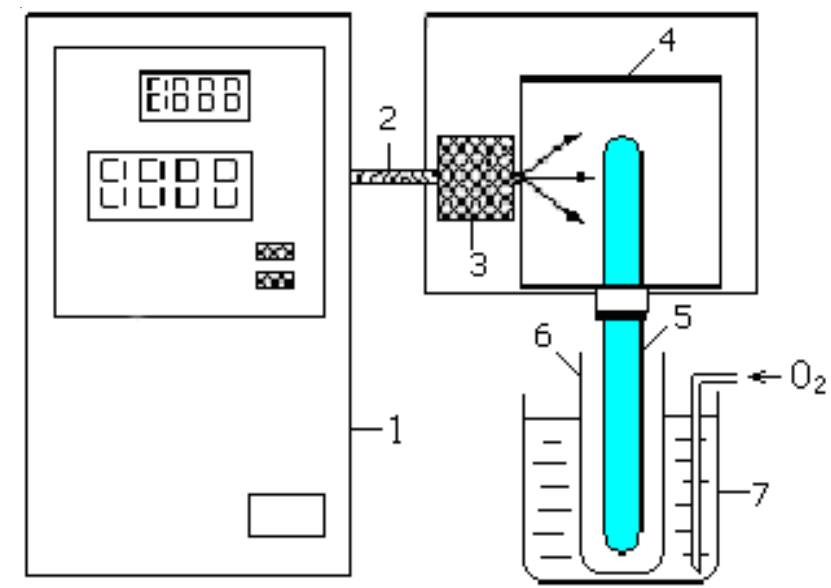

Fig. 2. Schematic of MDEIL: (1) microwave generator, (2) electrical cable, (3) magnetron, (4) resonant cavity, (5) electrodeless discharge lamp, (6) quartz sleeve, and (7) container

The experiment was performed as follows. First, the essential characteristics and preparation parameters of MDEIL were examined to optimize several selected variables, including the amount of krypton, iodine and input power. According to a pre-existing research ${ }^{23}$, the emission spectrum of the MDEIL was preliminarily studied under two typical conditions: (1) krypton, 2 torr; iodine, $0.1 \mathrm{mg}$; and input power, $65 \mathrm{~W}$; and (2) krypton, 2 torr; iodine, $2 \mathrm{mg}$ and input power and $65 \mathrm{~W}$. The amounts of krypton, iodine and input power were then studied as experimental variables to determine the optimal preparation parameters of MDEIL. The performance of MDEIL was measured using the emission spectrum intensity (arbitrary unit, a.u.) at a certain emission line. Second, the effects of dimethyl phthalate photolysis were studied in two areas, namely, irradiation time and initial dimethyl phthalate concentration. Emission spectrum intensity was studied in two established initial dimethyl phthalate concentration $(60$ and 8 $\mathrm{mg} \mathrm{L}^{-1}$ ) at 0-40 min irradiation time and the range of emission line was from $220-320 \mathrm{~nm}$. The removal efficiency of dimethyl phthalate was calculated from 0 to $50 \mathrm{~min}$ irradiation time. The removal efficiency of dimethyl phthalate was investigated at a certain irradiation time at initial dimethyl phthalate concentrations ranging from $20-100 \mathrm{mg} \mathrm{L}^{-1}$. Third, the photoproduct was analyzed at a certain irradiation time and initial dimethyl phthalate concentration. Hence, the mechanism of the photolysis of dimethyl phthalate was analyzed.
MDEIL preparation: In this study, the major critical component of MDEIL was the quartz tube (electrodeless lamp) with an external diameter and length of $20 \mathrm{~mm}$ and $30 \mathrm{~cm}$, respectively. The tube was filled with krypton and excitable substance iodine under reduced pressure and then sealed at both ends.

A precise typical vacuum system for MDEIL quartz tube preparation is shown in Fig. 3. Cirkva et al. ${ }^{18}$ suggested that the electrodeless lamp blank (7) should first be cleaned with soapy water, washed with distilled water, aqueous $10 \%$ hydrofluoric acid and ethanol and then dried in a clean oven to obtain a high-quality MDEIL device. Second, stopcocks (2) and (4) were turned on and stopcock (3) was turned off. The vacuum pump (1) was then turned on to keep the system on vacuum status. The vacuum status was ready when the mercury manometer (6) indicated that the pressure in the system was $10^{-3} \mathrm{~Pa}$. Third, the vacuum pump (1) was turned off and then stopcock (3) was turned on. The krypton gas tank (5) was turned on to flush the system with krypton. Stopcocks (2) to (4) and the krypton gas tank (5) were turned off quickly when the mercury manometer (6) indicated that the pressure has reached a certain value. At the same time, the sealing position (10) was sealed using a burner as soon as possible. Fourth, all devices of the system were dislodged except the thin branch pipe (7), iodine bottle (8) and electrodeless lamp blank (9). The iodine bottle (8) was then turned around to place a certain amount of iodine (as the electrodeless lamp filling material) to the electrodeless lamp blank (9) through the thin branch pipe (7). Finally, the sealing position (11) was sealed by a burner and the end was rounded.

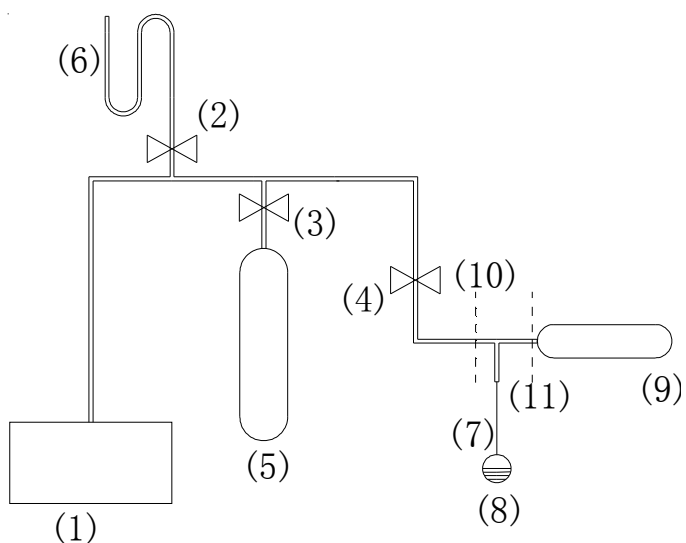

Fig. 3. Schematic of the vacuum system for MDEIL quartz tube preparation: (1) vacuum pump, (2) to (4) stopcocks, (5) krypton gas tank, (6) mercury manometer, (7) thin branch pipe, (8) iodine bottle, (9) electrodeless lamp blank, (10) and (11) sealing positions

Analytical method and experimental equipment: The $\mathrm{pH}$ of all solutions was measured using the PHS-2C pH-meter (Weiye Instrument Co., Shanghai, P.R. China). The emission spectrum of MDEIL was measured using the VM-505 VUV monochrometer (Acton, USA) and OceanOptics USB2000 UV-visible spectrometer. The devices used for MDEIL preparation, including the oven, stopcocks, vacuum pump, mercury manometer and burner, were all purchased from Boxun Co., Shanghai, P.R. China. The absorbance of dimethyl phthalate was detected using the S-3100 photodiode array UV-visible 
spectrometer (Republic of Korea, Scinco Company) and the photoproducts were analyzed using the MAT ITD800 GC-MS (Finnigan, USA). The dimethyl phthalate removal efficiency was calculated as

$$
\mathrm{R}=\frac{\mathrm{C}_{0}-\mathrm{C}}{\mathrm{C}_{0}} \times 100 \%
$$

where $\mathrm{C}_{0}$ and $\mathrm{C}$ are the initial and final concentrations ( $\left.\mathrm{mg} \mathrm{L}^{-1}\right)$ of dimethyl phthalate.

\section{RESULTS AND DISCUSSION}

Characteristics of the MDEIL: The procedure for MDEIL preparation, facilitating the reproduction of these methods in the laboratory to develop a MDEIL that possess the same properties as previously described. Several selected variables were also optimized. These preparation parameters of MDEIL are important for the performance investigation.

Emission spectrum: The microwave input power and krypton was fixed at $65 \mathrm{~W}$ and 2 Torr, respectively. The emission spectra of the MDEIL under 2 and $0.1 \mathrm{mg}$ iodine are shown in Fig. 4a-b, respectively. The emission spectra of the MDEIL were measured using the VM-505 VUV monochrometer (Acton, USA), which generated different values. Fig. 4a shows that the MDEIL containing $2.0 \mathrm{mg}$ iodine emitted six atomic iodine emission lines at 178.3, 180.1, 183 $\left(5 \mathrm{p}^{4} 6 \mathrm{~s}\left({ }^{4} \mathrm{P}_{5 / 2}\right)-5 \mathrm{p}^{5}\left({ }^{2} \mathrm{P}_{3 / 2}\right)\right), 184.4\left(5 \mathrm{p}^{4} 6 \mathrm{~s}\left({ }^{4} \mathrm{P}_{3 / 2}\right)-5 \mathrm{p}^{5}\left({ }^{2} \mathrm{P}_{1 / 2}\right)\right), 187.6$ $\left(5 p^{4} 6 s\left({ }^{4} \mathrm{P}_{1 / 2}\right)-5 p^{5}\left({ }^{2} \mathrm{P}_{1 / 2}\right)\right), 206.2 \mathrm{~nm}\left(5 \mathrm{p}^{4} 6 \mathrm{~s}\left({ }^{2} \mathrm{P}_{3 / 2}\right)-5 \mathrm{p}^{5}\left({ }^{2} \mathrm{P}_{1 / 2}\right)\right)$
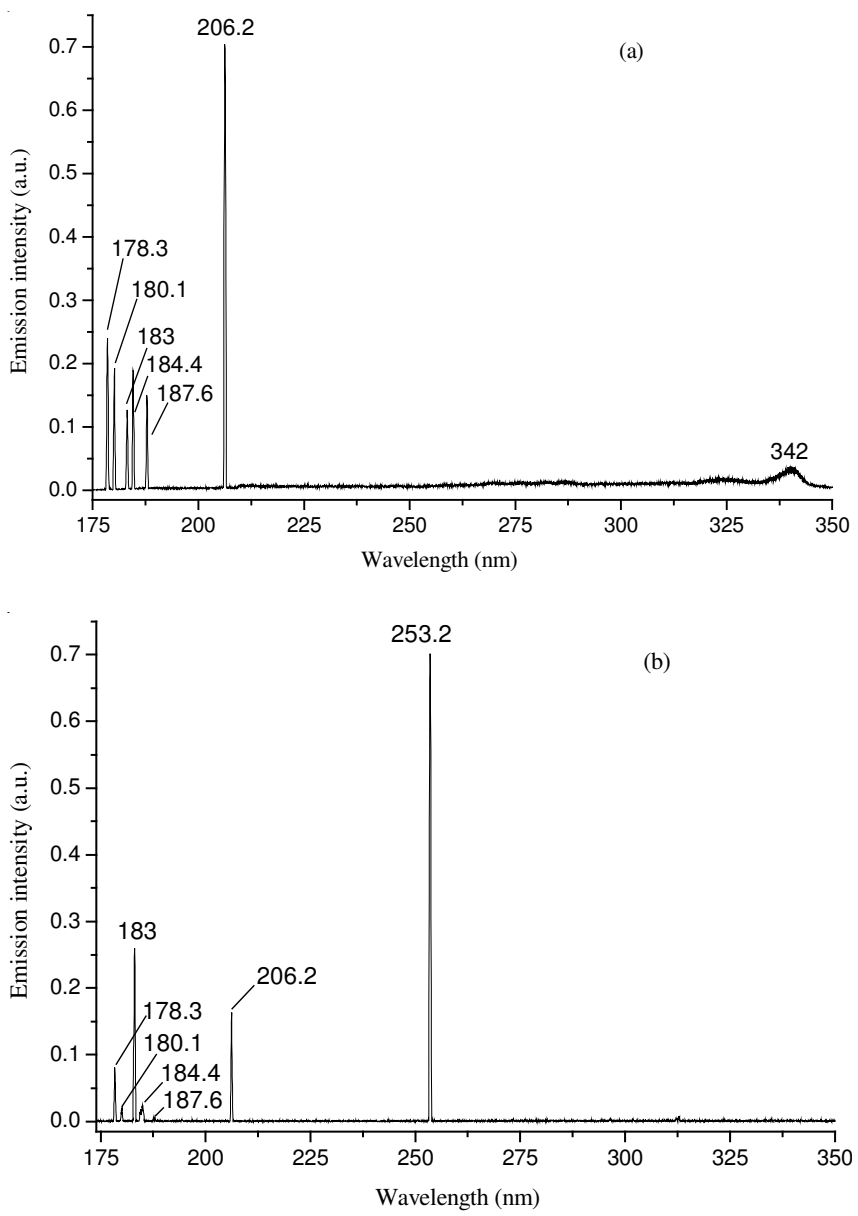

Fig. 4. Emission spectra of MDEIL: (a) 2 and (b) $0.1 \mathrm{mg}$ iodine and one excitation state $\mathrm{I}_{2} *$ emission line at $342 \mathrm{~nm}$. The maximal and minimal emissions were at 206.2 and $342 \mathrm{~nm}$, respectively. The emission spectrum intensities of the other emission lines were similar and their sum approached the 206.2 $\mathrm{nm}$ emission spectrum intensity. These results were in agreement to those in literature ${ }^{25}$. Fig. $4 \mathrm{~b}$ shows that the MDEIL containing $0.1 \mathrm{mg}$ iodine also emitted 178.3, 180.1, 183, 184.4, 187.6 and $206.2 \mathrm{~nm}$ emission lines, but their emission spectrum intensities were quite different. The $183 \mathrm{~nm}$ emission line represented an extremely higher intensity than the others. However, a new emission spectrum was detected at $253.2 \mathrm{~nm}$ emission line, which was also the maximal emission. The maximal emission $206.2 \mathrm{~nm}$ in Fig. 4a was very weak in Fig. 4b.

A series of complicated reactions occurred with kryptoniodine mixture gas in the MDEIL.

$$
\begin{gathered}
\mathrm{e}^{*}+\mathrm{Kr} \rightarrow \mathrm{Kr}^{*}+\mathrm{e} \\
\mathrm{e}^{*}+\mathrm{Kr} \rightarrow \mathrm{Kr}++2 \mathrm{e} \\
\mathrm{e}^{*}+\mathrm{I}_{2} \rightarrow \mathrm{I}^{-}+\mathrm{I}
\end{gathered}
$$

The iodine vapour pressure in the MDEIL containing 2 $\mathrm{mg}$ iodine was enough to proceed a triple-collision reaction because of the higher collision probability ${ }^{26}$.

The quasimolecule $\mathrm{KrI}^{*}$ was then obtained through the triple-collision reaction ${ }^{27,28}$.

$$
\mathrm{I}^{-}+\mathrm{Kr}^{+}+\mathrm{M} \rightarrow \mathrm{KrI}^{*}+\mathrm{M}
$$

where $\mathrm{M}$ is a triple-collision particle.

The excitation state I* was mainly obtained from the predecomposition of $\mathrm{KrI}^{*}$.

$$
\mathrm{KrI} * \rightarrow \mathrm{Kr}+\mathrm{I}^{*}
$$

The excitation state I* exhibited a relatively higher energy level, thus, its return-to-ground state mainly emitted emission lines at $206.2 \mathrm{~nm}^{27,28}$. At the same, the $253.2 \mathrm{~nm}$ emission line was not detected (Fig. 4a).

$$
\mathrm{I}^{*} \rightarrow \mathrm{I}+\mathrm{h} v(178.3,180.1,183,184.4,187.6,206.2 \mathrm{~nm})(7)
$$

The excitation state $\mathrm{Kr}^{*}$ also reacted with $\mathrm{I}_{2}$ when MDEIL contained $2 \mathrm{mg}$ iodine. The product $\mathrm{I}_{2} *$ mainly emitted emission lines at $342 \mathrm{~nm}$ during its return-to-ground state process (Fig. 4a).

$$
\begin{gathered}
\mathrm{Kr}^{*}+\mathrm{I}_{2} \rightarrow \mathrm{Kr}+\mathrm{I}_{2}{ }^{*} \\
\mathrm{I}_{2} * \rightarrow \mathrm{I}+\mathrm{I}+\mathrm{hv}(342 \mathrm{~nm})
\end{gathered}
$$

However, iodine vapour pressure in MDEIL containing $0.1 \mathrm{mg}$ iodine was too low to proceed into a triple-collision reaction because of lower collision probability ${ }^{26}$. Thus, only reactions (2) to (4) were obtained. Furthermore, the excitation state I* was mainly obtained from the reaction of high-energy electron in this situation.

$$
\mathrm{e}^{*}+\mathrm{I} \rightarrow \mathrm{I}^{*}+\mathrm{e}
$$

The excitation state $I^{*}$ exhibited relatively lower energy level, thus its return-to-ground state only emitted emission lines at $253.2 \mathrm{~nm}$ (Fig. 4b) $)^{26-28}$.

$$
\mathrm{I}^{*} \rightarrow \mathrm{I}+\mathrm{hv}(253.2 \mathrm{~nm})
$$

Moreover, the emission spectra of 0.5, 1.0, 3.0 and 4.0 $\mathrm{mg}$ iodine were similar to that of $2 \mathrm{mg}$ iodine (Fig. $4 \mathrm{a}$ ). In conclusion, emission spectrum intensity at $206.2 \mathrm{~nm}$ emission line was utilized as a measurement criteria to achieve optimized iodine amount, i.e., between 0.5 and $4.0 \mathrm{mg}$. 
Iodine: The $206.2 \mathrm{~nm}$ emission intensity of MDEIL (measured by OceanOptics USB2000 UV-VIS spectrometer) with varying amount of iodine at fixed 2 Torr krypton and $65 \mathrm{~W}$ input power are illustrated in Fig. 5. The emission spectrum intensity decreased with an increasing amount of iodine. The maximal emission spectrum intensity of $206.2 \mathrm{~nm}$ emission line was obtained at $0.5 \mathrm{mg}$ iodine. This emission spectrum intensity should be enough to directly decompose dimethyl phthalate $^{23}$. The trend that iodine vapour pressure in MDEIL increased with increasing iodine amount. The higher an iodine vapour pressure is obtained, the higher the probability that a triple-collision reaction will occur, indicating that more quasimolecule $\mathrm{KrI}^{*}$ would be obtained (eqn. 5). Therefore, emission spectrum intensity should theoretically increase with increasing iodine amount (eqns. 6 and 7), contrary to the experimental results (Fig. 5). However, this contradiction can be explained by two theories.

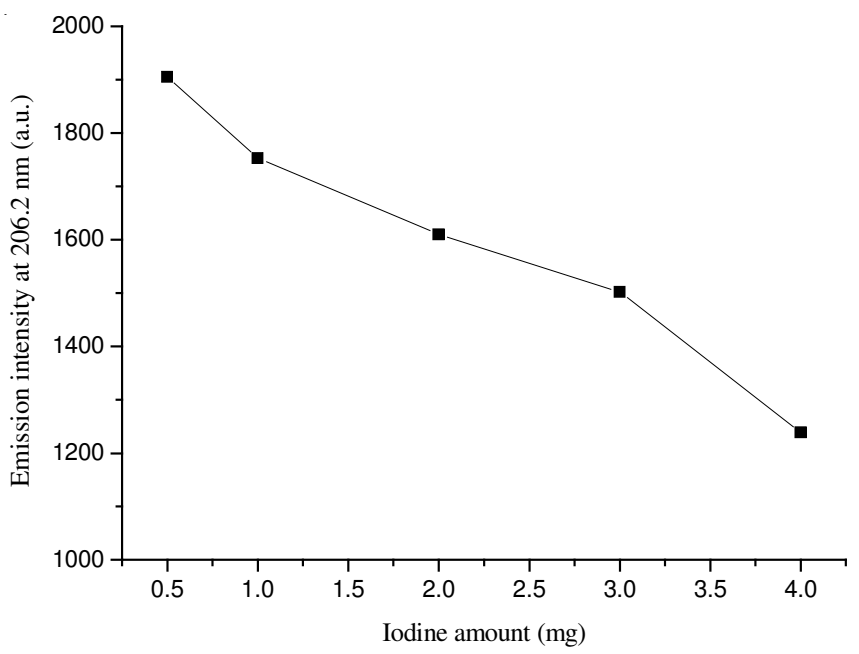

Fig. 5. Relationships between emission spectrum intensity and iodine amount

First, if a higher iodine vapour pressure is obtained, the higher the probability of quench reactions. This theory indicates that the quasimolecule $\mathrm{KrI}^{*}$ was most possibly decomposed to $\mathrm{Kr}$ and $\mathrm{I}$ through $\mathrm{I}_{2}$ collision $^{26-28}$.

$$
\mathrm{KrI}^{*}+\mathrm{I}_{2} \rightarrow \mathrm{Kr}+3 \mathrm{I}
$$

Second, the higher iodine vapour pressure is obtained, the shorter the mean free path of electrons will be $\mathrm{e}^{29}$. This theory signifies that there was insufficient energy for the reactions of eqns. 2-4 to proceed. Thus, relatively less quasimolecule $\mathrm{KrI}^{*}$ would be obtained through triple-collision reaction (eqn. 5) because of insufficient $\mathrm{I}^{-}$and $\mathrm{Kr}^{+}$. Consequently, the predecomposition of $\mathrm{KrI}^{*}$ (eqn. 6) and its return-to-ground state from excitation state $I^{*}$ (eqn. 7) disappears.

Krypton pressure: The $206.2 \mathrm{~nm}$ emission intensity of MDEIL (measured by the VM-505 VUV monochrometer) with varying amount of krypton pressure at fixed $2.0 \mathrm{mg}$ iodine and $65 \mathrm{~W}$ input power is illustrated in Fig. 6. The emission spectrum intensity decreased as the krypton pressure increased. The maximal emission spectrum intensity of $206.2 \mathrm{~nm}$ was obtained at 1 torr krypton pressure (Fig. 6). This trend can also be explained by the quench reactions and the mean free path of electrons theory.

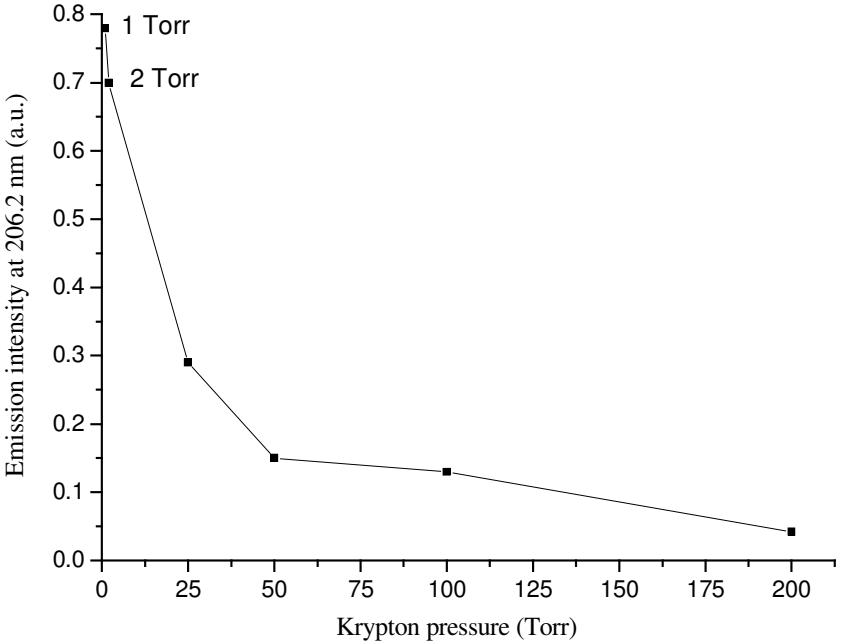

Fig. 6. Relationships between emission spectrum intensity and krypton pressure

First, a higher krypton pressure indicates more probability for quench reactions to occur. This condition indicates that quasimolecule $\mathrm{KrI}^{*}$ was most likely decomposed to the triatomic quasimolecule $\mathrm{Kr}_{2} \mathrm{I}^{*}$ and $\mathrm{Kr}$ through $\mathrm{Kr}$ collision ${ }^{26-28}$.

$$
\mathrm{KrI}^{*}+2 \mathrm{Kr} \rightarrow \mathrm{Kr}_{2} \mathrm{I}^{*}+\mathrm{Kr}
$$

Second, a higher krypton pressure results in shorter mean free path of electrons ${ }^{29}$. This condition indicates an energy shortage in the reactions of eqns. 2-4.

Hence, according to the analyses, the maximal emission spectrum intensity of $206.2 \mathrm{~nm}$ should be obtained when the iodine amount is below $0.5 \mathrm{mg}$ and krypton pressure is below 1 torr. However, considering the convenience and operability of MDEIL preparation process (step 4), the acceptable and reasonable optimal iodine amount in this article was $0.5 \mathrm{mg}$ and the logical and agreeable, optimal krypton pressure was 2 torr.

Input power: The emission spectrum intensity at 206.2 $\mathrm{nm}$ at fixed $1 \mathrm{mg}$ iodine and 1 torr krypton pressure with varying input power is illustrated in Fig. 7. The emission spectrum intensity was proportional to the input power, but the rate of change was obviously different before and after the input power reached $65 \mathrm{~W}$. The emission spectrum intensity initially increased rapidly as the input power increased. However, when the input power was more than $65 \mathrm{~W}$, the upward trend evidently slowed down. This trend can also be explained by the following theories. A higher input power brought more energy, which could be utilized to conduct the reactions in eqns. 2-4. This condition indicates that more quasimolecule KrI* was obtained through the reaction of eqn. 5 because of higher collision probability ${ }^{26}$. The higher emission spectrum intensity of emission line at $206.2 \mathrm{~nm}$ was then obtained (eqns. 6 and 7$)$.

However, the emission spectrum intensity was limited for cases with certain iodine amount and krypton pressure ${ }^{27,29}$. The degree of ionization (eqns. 2-4) was close to saturation and an inflection point ( $65 \mathrm{~W}$ in this situation) appeared when input power reached a certain value. Subsequently, the increment energy (input power) cannot be utilized effectively and is therefore wasted when input power was more than $65 \mathrm{~W}$. Furthermore, 


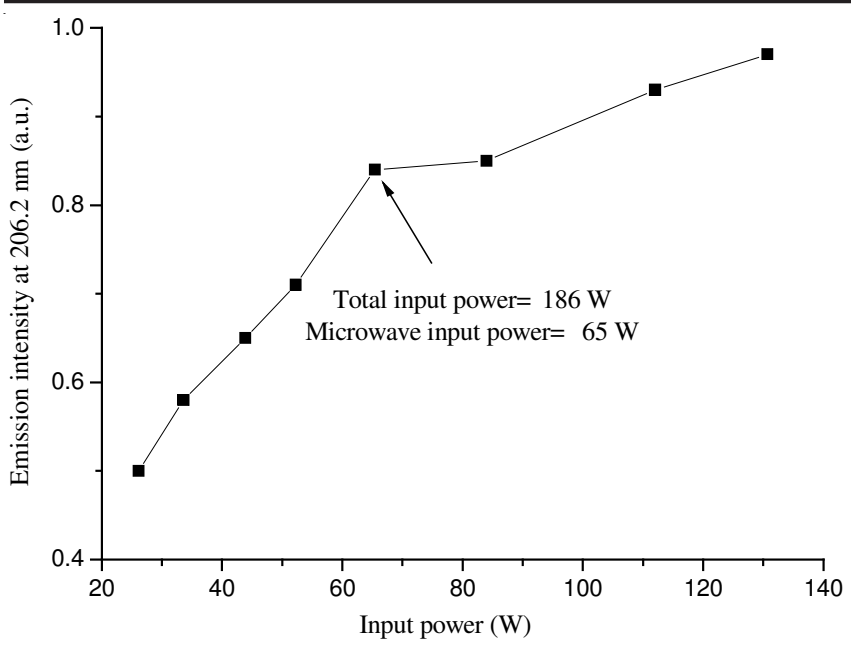

Fig. 7. Relationships between emission spectrum intensity and input power

the discharging arc shimmered tempestuously when input power was more than $80 \mathrm{~W}$. This phenomenon may have originated from the reflex and heat converting of the increment energy, which cannot be used completely ${ }^{29}$. The shimmering discharging arc can damage the MDEIL device badly. Hence, considering energy conservation, stability and adequate emission spectrum intensity, the optimal input power is $65 \mathrm{~W}$.

Accordingly, the optimal preparation parameters of MDEIL were determined as follows: iodine, $0.5 \mathrm{mg}$; krypton pressure, 2 torr and input power $65 \mathrm{~W}$. The MDEIL, which was utilized to decompose the dimethyl phthalate in this research, can then be prepared according to these three parameters and the MDEIL preparation procedure mentioned before.

\section{Effects of dimethyl phthalate photolysis}

Irradiation time: Fig. $1 \mathrm{~b}$ shows that the absorption peaks of the absorbance spectrum of untreated dimethyl phthalate solution were at 276 and $235 \mathrm{~nm}$. The absorption peaks at 276 and $235 \mathrm{~nm}$ were from the $\mathrm{R}$ absorption band of $\mathrm{n} \rightarrow \pi *$ transition of carbonyl and the intrinsic absorption band of $\pi \rightarrow \pi^{*}$ transition of benzene ring, respectively ${ }^{10,16}$. Two kinds of dimethyl phthalate solution ( 60 and $8 \mathrm{mg} \mathrm{L}^{-1}$ ) were both treated by the prepared MDEIL at 0,10, 20, 30 and $40 \mathrm{~min}$. The absorbance spectra of the 60 and $8 \mathrm{mg} \mathrm{L}^{-1}$ dimethyl phthalate solution are illustrated in Fig. 8a-b, respectively. The absorption peaks at 235 and $276 \mathrm{~nm}$ both exhibited a diminishing trend along with the extension of irradiation time until they totally disappeared.

Fig. 8a shows that the crest of absorption peak at $276 \mathrm{~nm}$ became wider and moved up along with the extension of irradiation time until it completely disappeared. The absorption peak then vanished at $40 \mathrm{~min}$. The increasing absorbance did not represent the enhancement of the carbonyl absorbance band. This phenomenon can be explained by the theory that the carbonyl group of dimethyl phthalate was decomposed into $\mathrm{C}-\mathrm{C}$ and/or $\mathrm{C}-\mathrm{O}$ bond by the MDEIL treatment, which then brought more $\sigma \rightarrow \sigma^{*}$ transitions that exhibited the increasing absorbance of dimethyl phthalate. On the other hand, the absorption peak of the benzene ring of dimethyl phthalate at $235 \mathrm{~nm}$ varied gradually along with prolonged irradiation time. The absorption peak was still evident at 40 min, but the absorbance value remarkably dropped in contrast
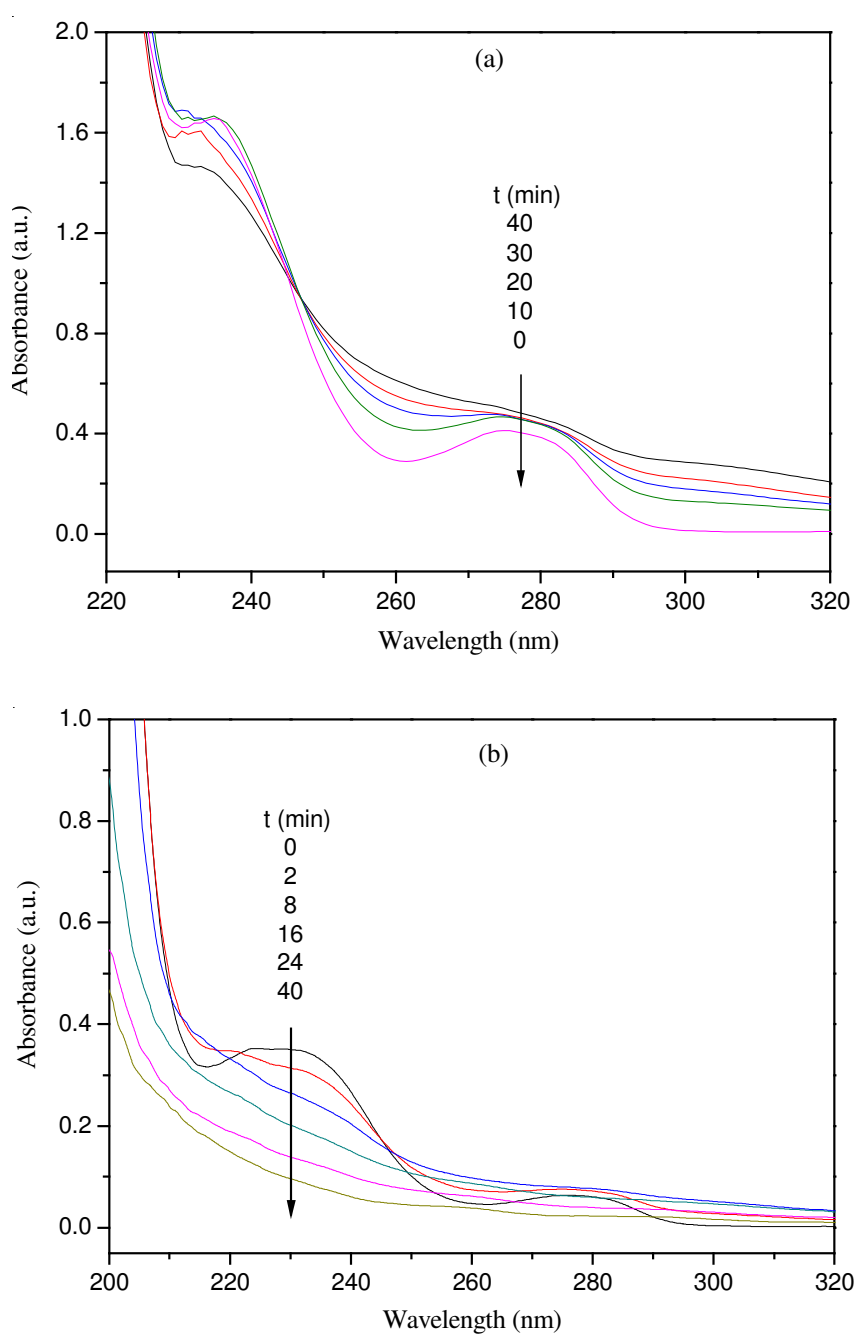

Fig. 8. Absorbance spectra of dimethyl phthalate solutions: (a) $60 \mathrm{mg} \mathrm{L}^{-1}$ and (b) $8 \mathrm{mg} \mathrm{L}^{-1}$ concentration

to the untreated dimethyl phthalate solution. Therefore, the benzene ring of dimethyl phthalate was effectively broken via the MDEIL treatment (Fig. 8a).

The absorbance spectrum of dimethyl phthalate at $8 \mathrm{mg}$ $\mathrm{L}^{-1}$ dimethyl phthalate varied dramatically along with prolonged irradiation time (Fig. 8b). Prior to $8 \mathrm{~min}$, the variation tendency of absorption peaks at 276 and $235 \mathrm{~nm}$ were similar to that of $60 \mathrm{mg} \mathrm{L}^{-1}$ dimethyl phthalate solution (Fig. 8a). In case of the relatively low concentration $\left(60 \mathrm{mg} \mathrm{L}^{-1}\right)$, the absorption peaks at 276 and $235 \mathrm{~nm}$ disappeared after only $8 \mathrm{~min}$. The two peaks became a smooth curve (Fig. 8b) along with further extension of irradiation time. The absorbance spectrum of $\mathrm{C}-\mathrm{C}$ and/or C-O bond was dominant at this point.

Therefore, the reaction mechanism of dimethyl phthalate photolysis emerged. The product of decomposed carbonyl and benzene ring can be further degraded into macromolecule hydrocarbons. Hence, the absorbance spectrum of $\sigma \rightarrow \sigma^{*}$ transition of $\mathrm{C}-\mathrm{C}$ and $\mathrm{C}-\mathrm{O}$ bond decreased along with prolonged irradiation time.

The relationship between the removal efficiency of dimethyl phthalate and irradiation time at $60 \mathrm{mg} \mathrm{L}^{-1}$ dimethyl phthalate concentration is illustrated in Fig. 9. The removal efficiency of dimethyl phthalate increased as irradiation time increased. The maximal removal efficiency was approximately 


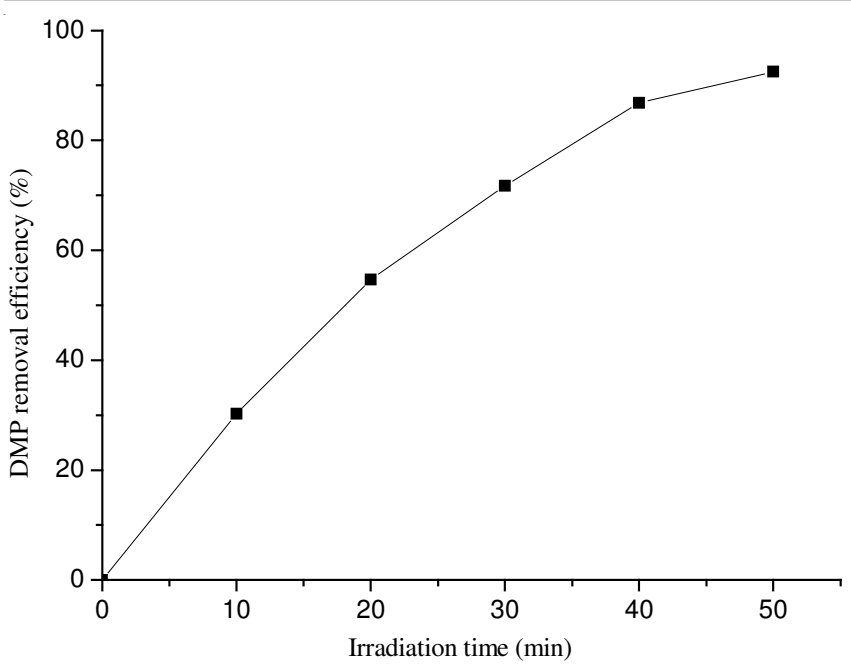

Fig. 9. Relationships between removal efficiency of dimethyl phthalate and irradiation time

$92.5 \%$ at 50 min irradiation time. However, ca. $85.0 \%$ removal efficiency was already reached at 40 min irradiation time.

Initial concentration of dimethyl phthalate: The relationship between removal efficiency of dimethyl phthalate and concentration of dimethyl phthalate at 20 min irradiation time is illustrated in Fig. 10. dimethyl phthalate removal efficiency decreased as irradiation time increased. The removal efficiency reached $97.5 \%$ at $20 \mathrm{mg} \mathrm{L}^{-1}$ initial dimethyl phthalate concentration. This phenomenon was probably caused by an increase in the molecular number of dimethyl phthalate as dimethyl phthalate concentration increased. Hence, the emission spectrum intensity of MDEIL cannot meet the demand of photolysis of relatively excessive dimethyl phthalate molecules at a fixed irradiation time when the molecular number reaches a certain value. Moreover, a higher dimethyl phthalate concentration results in more intermediates that can compete with dimethyl phthalate for photon. This condition also reduced the dimethyl phthalate removal efficiency. As a result, the irradiation time should be appropriately prolonged when initial concentration of dimethyl phthalate was relatively high.

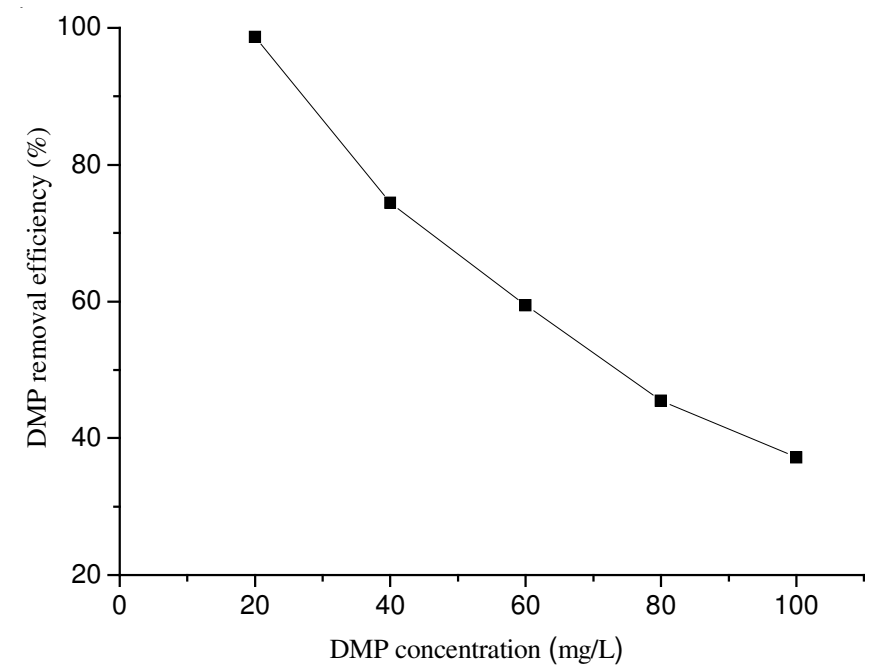

Fig. 10. Relationships between removal efficiency of dimethyl phthalate and dimethyl phthalate concentration
Therefore, simultaneously considering productivity and decomposing effects, the preferred recommended value of irradiation time and initial concentration are $20 \mathrm{~min}$ and 20 $\mathrm{mg} \mathrm{L}^{-1}$, respectively.

Identification of intermediates and proposed of mechanism: The formation of intermediate products was studied on the condition that initial concentration of dimethyl phthalate and irradiation time were $60 \mathrm{mg} \mathrm{L}^{-1}$ and $10 \mathrm{~min}$, respectively. The GC-MS chromatograms of dimethyl phthalate degradation are shown in Fig. 11. The main peak represented dimethyl phthalate $\left(t_{R}=10.03 \mathrm{~min}\right)$. The intermediates identified were phthalic acid methyl ester $\left(t_{R}=9.58 \mathrm{~min}\right)$ and 2-hydroxyl acid methyl ester $\left(t_{R}=8.68 \mathrm{~min}\right)$. Identification was performed using the NIST database of GC-MS ${ }^{30}$. The molecular structures of phthalic acid methyl ester and 2-hydroxyl acid methyl ester are illustrated in Figs. 12a-b, respectively.

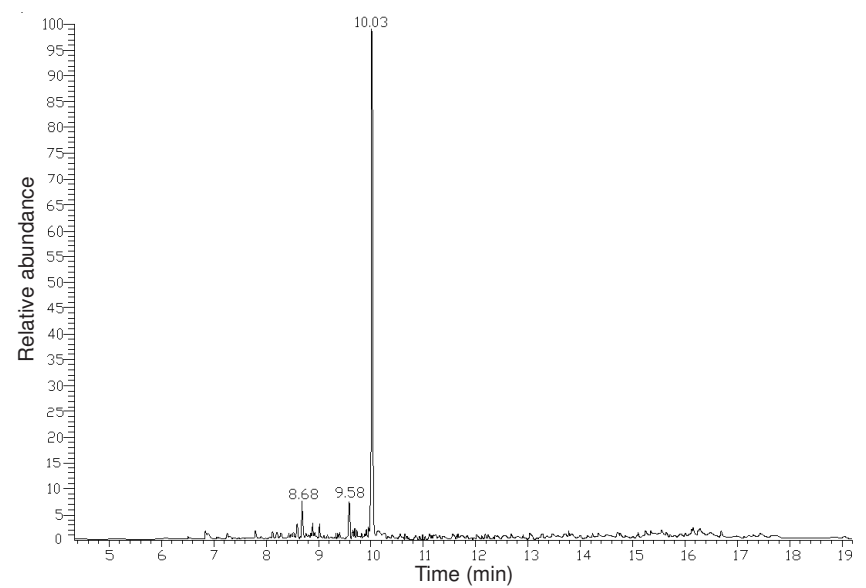

Fig. 11. GC-MS chromatograms of dimethyl phthalate degradation<smiles>COC(=O)c1ccccc1C(=O)O</smiles>

(a)<smiles>COC(=O)c1ccccc1O</smiles>

(b)
Fig. 12. Molecular structures of (a) phthalic acid and (b) 2-hydroxyl acid methyl esters

In addition, the absorption coefficient $(\varepsilon)$ of the dimethyl phthalate solution at $206.2 \mathrm{~nm}$ emission line was $7.4 \times 10^{3} \mathrm{M}^{-1}$ $\mathrm{cm}^{-1}$ according to the calculation of the Lambert-beer's law ${ }^{31}$. The molar concentration of dimethyl phthalate was calculated as $3 \times 10^{-4} \mathrm{~mol} \mathrm{~L}^{-1}$. In the saturated solution of oxygen at 25 ${ }^{\circ} \mathrm{C}$, the absorption coefficient $(\varepsilon)$ at $206.2 \mathrm{~nm}$ emission line and molar concentration of oxygen were $2.4 \times 10^{-3} \mathrm{M}^{-1} \mathrm{~cm}^{-1}$ and $1.29 \times 10^{-3} \mathrm{~mol} \mathrm{~L}^{-1}$, respectively ${ }^{32}$. Hence, the ratio of dimethyl phthalate and oxygen absorbed photon numbers can be calculated as:

$$
\begin{aligned}
& \frac{\mathrm{n}_{(\mathrm{DMP}, \mathrm{abs})}}{\mathrm{n}_{\left(\mathrm{O}_{2}, \mathrm{abs}\right)}}=\frac{\varepsilon_{\mathrm{DMP}} \mathrm{M}_{\mathrm{DMP}}}{\varepsilon_{\mathrm{O}_{2}} \mathrm{M}_{\mathrm{O}_{2}}} \\
= & \frac{7.4 \times 10^{3} \times 3.09 \times 10^{-3}}{2.4 \times 10^{-3} \times 1.29 \times 10^{-3}}=7.39 \times 10^{5}
\end{aligned}
$$


Eqn. 14 shows that the absorbed photon number of oxygen can be ignored because the absorbed photon number of dimethyl phthalate was extremely larger than that of oxygen. Therefore, photolysis of dimethyl phthalate in oxygensaturated solution was mainly due to the $206.2 \mathrm{~nm}$ emission line from MDEIL.

A plausible mechanism for the photolysis of dimethyl phthalate involving electron transition reactions and reactions with hydroxyl radicals is proposed, as shown in eqns. 15$17^{6,10,13,16}$.

Direct photolysis of dimethyl phthalate by the $206.2 \mathrm{~nm}$ emission line was obtained from MDEIL.

$$
\mathrm{DMP} \stackrel{\mathrm{hv}(206.2 \mathrm{~nm})}{\longrightarrow} \mathrm{DMP}^{*} \longrightarrow
$$
${ }^{\circ} \mathrm{CHO}$.

Oxidation of ${ }^{\bullet} \mathrm{CH}_{3}$ to $\mathrm{CH}_{3} \mathrm{O}_{2}{ }^{\bullet}$ and further dehydration to

$$
\cdot \mathrm{CH}_{3}+\mathrm{O}_{2} \longrightarrow \mathrm{CH}_{3} \mathrm{O}_{2} \longrightarrow \cdot \mathrm{CHO}+\mathrm{H}_{2} \mathrm{O}
$$

Substitution of the main product of eqn. 15 and further decomposition to the final product, $\mathrm{CO}_{2}$ and $\mathrm{H}_{2} \mathrm{O}$.

$$
\stackrel{h v(206.2 \mathrm{~mm})}{\longrightarrow} \mathrm{Ri}_{i}^{*}+\text { fragment } \rightarrow \ldots \rightarrow \text { The final product }+\mathrm{CO}_{2}+\mathrm{H}_{2} \mathrm{O}
$$

\section{Conclusion}

Our results demonstrated, for the first time, that 206.2 nm UV light emitted from a locally made novel MDEIL can photodegrade dimethyl phthalate effectively. This phenomenon is different from other traditional photolysis process because of the applied emission line (206.2 nm) and unique contraption. The essential characteristics and optimal preparation parameters of MDEIL were determined as follows: iodine, $0.5 \mathrm{mg}$; krypton pressure, 2 torr and input power, $65 \mathrm{~W}$. The feasibility of using the proposed MDEIL device and photolysis technology was proven by the degradation efficiency of dimethyl phthalate. The removal efficiency approaches $97.5 \%$ at 20 min irradiation time and $20 \mathrm{mg} \mathrm{L}^{-1}$ initial dimethyl phthalate concentration. The photolysis mechanism and degradation products of dimethyl phthalate were clarified. A possible mechanism of dimethyl phthalate photolysis may involve electron transition reactions and reactions with hydroxyl radicals. The intermediates identified were phthalic acid methyl ester and 2-hydroxy acid methyl ester. Hence, this research has shown that MDEIL, a novel UV source, can disintegrate organic contaminant. MDEIL may be able to remove most of the organic pollutants in wastewater because this research only focused on one refractory contaminant dimethyl phthalate. This study provides an alternative approach for the photolysis of more aqueous organic contaminants, including other refractory contaminant. However, the presence of an intermediate indicates that only a part of the target contaminant can be decomposed completely by the MDEIL. Therefore, further optimization of the MDEIL is still necessary and urgent.

\section{ACKNOWLEDGEMENTS}

The authors thank colleagues and students from Fudan University for maintaining the treatment systems during the study period. The authors are also very grateful to Naomi Cappuccino, Department of Biology, Carleton University, for comments on a draft manuscript. This study was financially supported by the National Water Special Project of China (No. 2008ZX07101-001-04) and Education Departmentof Anhui Province (Grant Nos. KJ2008A137).

\section{REFERENCES}

1. M.J. Bauer and R. Hermann, Sci. Total. Environ., 208, 49 (1997).

2. C.A. Staples, D.R. Peterson, T.F. Parkerton and W.J.Adams, Chemosphere, 35, 667 (1997).

3. D. Balafas, K.J. Shaw and F.B. Whitfield, Food Chem., 65, 279 (1999).

4. L.H. Keith and W.A. Telliard, Environ. Sci. Technol., 13, 416 (1979).

5. Y.Y. Wang, Y.Z. Fan and J.D. Gu, Int. Biodeterior. Biodegrad., 53, 93 (2004).

6. X.K. Zhao, G.P. Yang, Y.J. Wang and X.C. Gao, J. Photochem. Photobiol. A, 161, 215 (2004).

7. C.R. Tyler, S. Jobling and J.P. Sumpter, Crit. Rev. Toxicol., 28, 319 (1998).

8. S. Jobling, T. Reynolds, R. White, M.G. Parker and J.P. Sumpter, Environ. Health Perspect., 103, 582 (1995).

9. M. Allsopp, D. Santillo and P. Johnston, Poisoning the Future: Impacts of Endocrine-Disrupting Chemicals on Wildlife and Human Health, Greenpeace International, Ijmuiden, pp. 5/17-5/24 (1997).

10. P. Liang, J. Xu and Q. Li, Anal. Chim. Acta, 609, 53 (2008).

11. H. Zhang, X.Q. Chen and X.Y. Jiang, Anal. Chim. Acta, 689, 137 (2011).

12. Introduction to Water Policy Standards, US Environmental Protection Agency, Office of Water, Washington D.C., pp. 3/43-3/57 (1999).

13. B.L. Yuan, X.Z. Li and N. Graham, Chemosphere, 72, 197 (2008).

14. W.J. Adams, G.R. Biddinger, K.A. Robillard and J.W. Gorsuch, Environ. Toxicol. Chem., 14, 1569 (1995).

15. J.E. Rhodes, W.J. Adams, G.R. Biddinger, K.A. Robillard and J.W. Gorsuch, Environ. Toxicol. Chem., 14, 1967 (1995).

16. J. Xu, P. Liang and T.Z. Zhang, Anal. Chim. Acta, 597, 1 (2007).

17. G. Hizal, Q.Q. Zhu, C.H. Fischer, P.M. Frirz and W.J. Schnahel, J. Photochem. Photobiol. A, 72, 147 (1993).

18. V. Cirkva, L. Vlkova, S. Relich and M. Hajek, J. Photochem. Photobiol. A, 179, 229 (2006).

19. J.L. Weeks, G.M.A.C. Meabum and S. Gordon, Radiat. Res., 19, 559 (1963).

20. E.G. Janzen, Y. Kotake and R.D. Hinton, Free Radic. Biol. Med., 12, 169 (1992).

21. Q.M. Chen, C. Yang, N.K. Goh, K.C. Teo and B. Chen, Chemosphere, 55, 339 (2004).

22. L.Y. Zhao, C.Q. Cao, J.C. He, R.X. Zhang and H.Q. Hou, Chin. J. Chem., 20, 706 (2009).

23. L.Y. Xia, D.H. Gu, J. Tan, W.B. Dong and H.Q. Hou, Chemosphere, 71, 1774 (2008).

24. A.I. Al-Shamma'a, I. Pandithas and J. Lucas, J. Phys. D: Appl. Phys., 34, 2775 (2001).

25. J.S. Lin, W.P. Chu, F.S. Juang, N.P. Chen, Y.S. Tsai, C.C. Chen, C.M. Chen and L.C. Liu, Mater. Lett., 67, 42 (2012).

26. B. Gellert and U. Kogelschatz, Appl. Phys. B, 52, 14 (1991).

27. B. Eliasson and U. Kogelschatz, Plasma IEEE Trans. Plasma. Sci., 19, 309 (1991).

28. J.Y. Zhang and L.W. Boyd, J. Appl. Phys., 80, 633 (1996).

29. Y.E. Krasik, J.Z. Gleizer, A. Krokhmal, K. Chirko, A. Sayapin, J. Felsteiner, V. Bernshtam and V.I. Gushenets, Vacuum, 77, 391 (2005).

30. Z.H. Ai, P. Yang and X.H. Lu, J. Hazard. Mater., 124, 147 (2005).

31. H. Okabe, Photochemistry of Small Moleeules, Wiley, New York, pp. 5/18-5/43 (1978)

32. R.C. Weast and M.J. Astle, CRC Handbook of Chemistry and Physics, CRC Press, Boca Raton, pp. 3/25-3/57 (1982). 